\title{
Effect of Coconut Water on Root Induction of Musa (AA Group) 'KLUAI NAM THAI' In Vitro
}

\author{
Thanwamas Kassanuk ${ }^{1}$, Orapin Selakorn ${ }^{2}$, Khongdet Phasinam ${ }^{3 *}$, Sudarat Sutaphan ${ }^{4}$ \\ 1,2,3,4 Faculty of Food and Agricultural Technology, Pibulsongkram Rajabhat University, Thailand \\ Email: ${ }^{1}$ t.kassanuk@gmail.com, ${ }^{2}$ orapin@psru.ac.th, ${ }^{3}$ phasinam@psru.ac.th, ${ }^{4}$ ssutaphan@psru.ac.th
}

\begin{abstract}
'Kluai Nam Thai' (Musa AA group) are rare in Thailand and it is at risk of extinction because of environmental changes and human behavior. Hence, the plant tissue culture technique is used for propagation. This research aimed to study the effect of coconut water on root induction of Kluai Nam Thai in vitro. The shootlets from laboratory were cultured on Murashige and Skoog (MS) medium supplemented with coconut water at concentrations 10, 15, 20, and 25\% for 1 month. The experimental design was Completely Randomized Design (CRD). The results indicated that MS medium supplemented with $20 \%$ coconut water gave the highest average number of roots at 1.85 while MS medium supplemented with $10 \%$ coconut water gave the highest length of roots at $2.34 \mathrm{~cm}$ which were significantly different $(\mathrm{p}<0.01)$ from the other concentrations.
\end{abstract}

Keywords

Musa (AA group) 'Kluai Nam Thai’, Tissue Culture, Coconut Water, Micropropagation

\section{Introduction}

In Thailand, banana grants have been grown since the ancient time. There are local and imported species. There are many species such as Kluai Namwa, Kluai Hom and Kluai Nam Thai. In 2016, the total area for growing commercial bananas was $277.44 \mathrm{~km}^{2}$ [1] 'Kluai Nam Thai' (Musa acuminata). It is in the AA genome group. Its pseudostem is about 2.5 meters high. Its diameter is not wider than 15 centimeters. Its outer spathes are thick. Its outer and inner bases are red and pink. The stems of its leaves are upright. The grooves of the steams are wide. The edges of the stems are pink. The lines of the leaves are pink and red. The stems of the flowers have hairs. The bracts are oval and quite long. The tips of the bracts are pointy and rolled up. The upper parts of the tips are purple and red. The lower parts of the tips are light purple and red. Each bunch has about five clusters of bananas. Each cluster has about 12-18 bananas. The bananas are similar to Kluai Hom Chan. Each banana is 2.00-2.05 centimeters wide and 10-11 centimeters long. The bananas are not as curved as Kluai Hom Chan. The tips of the bananas are big, but the tips are smaller than that of Kluai Hom Chan. The tips of the bananas have pistils. The banana peels are thinker than that of Kluai Hom Chan. The bananas have good and cool smells. The ripened bananas are yellow and darker than Kluai Hom Chan. The peels of the ripened bananas have black spots similar to that of Kluai Khai. The banana pulp is yellow and orange. The pulp is sweet [2]. Kluai Nam Thai are local bananas found in some province in the central part of Thailand. The bananas are not widely known and reproduced, and people do not properly maintain banana plots. These affect the reproduction of the bananas. So, this species has extinction risk. To promote and reproduce the bananas, plant tissue culture is an alternative to reproduce many bananas within short periods of time. The plant tissue culture is a well-known method. Hence, plant tissue culture technique is used for propagation. The reproductive parts of living plants such as shoots, axillary bud, flower stems, leaves, petiole, stem, pollens and seeds are cultured on MS medium [3]. Tissue cultured plants have constant growths. By growing the plants, the plants can be harvested at the same time. Moreover, the plants are without from diseases and insects. The plants also do not have the limitations of natural propagation. Growth regulators are important for the plant tissue culture. There are five main groups of the growth regulators including cytokinin, auxin, gibberellins, abscisic acid and ethylene. Each group is important for the plant tissue culture. Mostly, the appropriate ratios of auxin and cytokinin are used in order to effectively grow shoots and roots [4]. Since the growth regulators are expensive, organic substances are used in order to replace the growth regulators. Coconut water has organic substances that have main roles in controlling the growths of plants. The substances include auxin, cytokinin, gibberellins, abscisic acid and salicylic acid. Auxin in the coconut water is an indole-3-acetic acid (IAA) that regulates the growths of plants as well as the developments of shoots, roots, raw coconuts and areas with many tissues [5], [6]. Cytokinin is a component and a group of hormones that can stimulate the growths of plants, cell divisions, and the developments of the apical bud [7]. N Sudhanyaratana and other [8] had the tissue culture and the analysis of ploidy stability of Musa (ABB) 'Namwa Mali-Ong'. The shoots of Kluai Namwa Mali-Ong were cultured on the MS medium [9] that 
N6-Benzyladenine (BA), $\alpha$-Naphthalene Acetic Acid (NAA) and coconut water were added to. There were 15 recipes of the cultures. The shoots were cultured for eight weeks. It was found that the MS medium supplemented with $15 \%$ coconut water could resulted in shoots induction for $100 \%$ and root average 1.40 roots per plant. This was consistent with $R$. Senavongse and other [10] who studied the appropriate amounts of the coconut water for the growth of Dendrobium Kontumense Gagnep, which was cultured on the MS medium at the six concentrations of the coconut water $(0 \%, 5 \%, 10 \%, 15 \%, 20 \%$ and $25 \%)$ for 8 weeks. It was found that the shoots cultured in the culture with the coconut water $(15 \%)$ resulted in 11.50 roots per part, and the average length of the roots was 7.89 centimeters. A. Enik and other [11] studied the effects of the concentrations of the coconut water and IAA on the growth of Tribulus (Tribulus Terrestris L.) in vitro. The concentrations of the coconut water were $0 \%, 5 \%, 10 \%$ and $15 \%$. The concentrations of IAA were $0.00 \mathrm{ppm}, 0.15 \mathrm{ppm}, 0.20 \mathrm{ppm}$ and $0.25 \mathrm{ppm}$. It was found that the coconut water with the concentration of $15 \%$ and IAA with the concentration of $0.25 \mathrm{ppm}$ could result in the highest number of roots (10.66 roots). The fastest period for developing the roots was 19.33 days.

According to the stated data, the plant tissue culture technique was used for reproducing 'Kluai Nam Thai' by studying the effects of the coconut water on the root induction in vitro. The research findings can be used as the guidelines for reproducing bananas by gardeners and other people interested in this technique in the future.

\section{Research Objectives}

The objective of this research aimed to study the effects of the coconut water on the root induction of 'Kluai Nam Thai' in vitro.

\section{Research Methods}

To study the effects of the coconut water on the root induction of Kluai Nam Thai in vitro, the MS medium was prepared by adding the coconut water with the concentrations of $10 \%, 15 \%, 20 \%$ and $25 \%$. The completely randomized design (CRD) was used. Each experiment was repeated for 4 times with 7 bottles per experiments. The shootlets with 2 or 3 leaves were selected from the laboratory bottles according to the study of O. Selakorn and other [12], and then the shoots were taken to the sterilized cabinets. Then, the shoots were taken out of the bottles. The shoots were cut from the parts in order to culture the shoots on the prepared MS medium for each experiment. The bottles were placed on the shelves in the rooms with the controlled temperatures of $25-28{ }^{\circ} \mathrm{C}$, the light intensities of 1,500-3,000 lux and the relative humidity of $60-80 \%$. The shoots were cultured for 1 month. The number of the roots per plant and the lengths of the roots were recorded. Then, the data were analyzed and compared statistically with Duncan's Multiple-Range Test (DMRT). The experimental procedure are presented in Fig. 1.

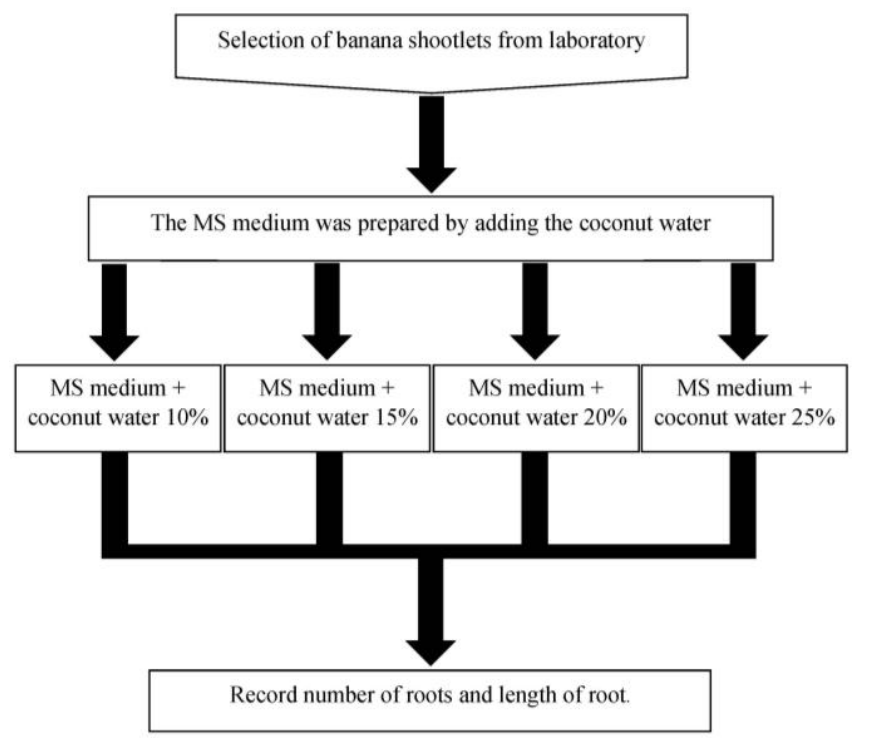

Fig. 1 Flow chart over all process

Results

From this studying the effects of the concentrations of the coconut water on the root induction of 'Kluai Nam Thai', the shootlets with 2 to 3 leaves from the culture bottles were selected and cultured on the MS medium have the coconut water with the concentrations of $10 \%, 15 \%, 20 \%$ and $25 \%$ for 1 month. It was found that the highest number of roots developed by using the coconut water with the concentration of $20 \%$ was 1.85 roots per plant, while the longest length of the roots developed by using the coconut water with the concentration of $10 \%$ was 2.34 centimeters as shown in Table 1. The roots were white, and the roots had many hairs (Fig. 2).

Table I Mean number of root and length of root of 'Kluai Nam Thai' cultured on MS medium Supplemented with various concentration of coconut water after 1 month of culturing.

\begin{tabular}{lcc}
\hline \multicolumn{1}{c}{ Treatment } & Number of Root & Length of Root (cm) \\
\hline MS medium + Coconut water 10\% & $1.57 \mathrm{ab}^{1 /}$ & $2.34 \mathrm{a}$ \\
MS medium + Coconut water 15\% & $1.28 \mathrm{~b}$ & $1.95 \mathrm{~b}$ \\
MS medium + Coconut water 20\% & $1.85 \mathrm{a}$ & $1.75 \mathrm{c}$ \\
MS medium + Coconut water 25\% & $0.28 \mathrm{c}$ & $0.85 \mathrm{~d}$ \\
\hline F-test & $* *$ & $* *$ \\
\hline C.V. (\%) & 38.00 & 10.47 \\
Remark 1/ Mean values followed by different letters in each column are significantly \\
different according to F-test and DMRT. \\
${ }^{* *}$ Significant difference at $\mathrm{P} \leq 0.01$ level.
\end{tabular}




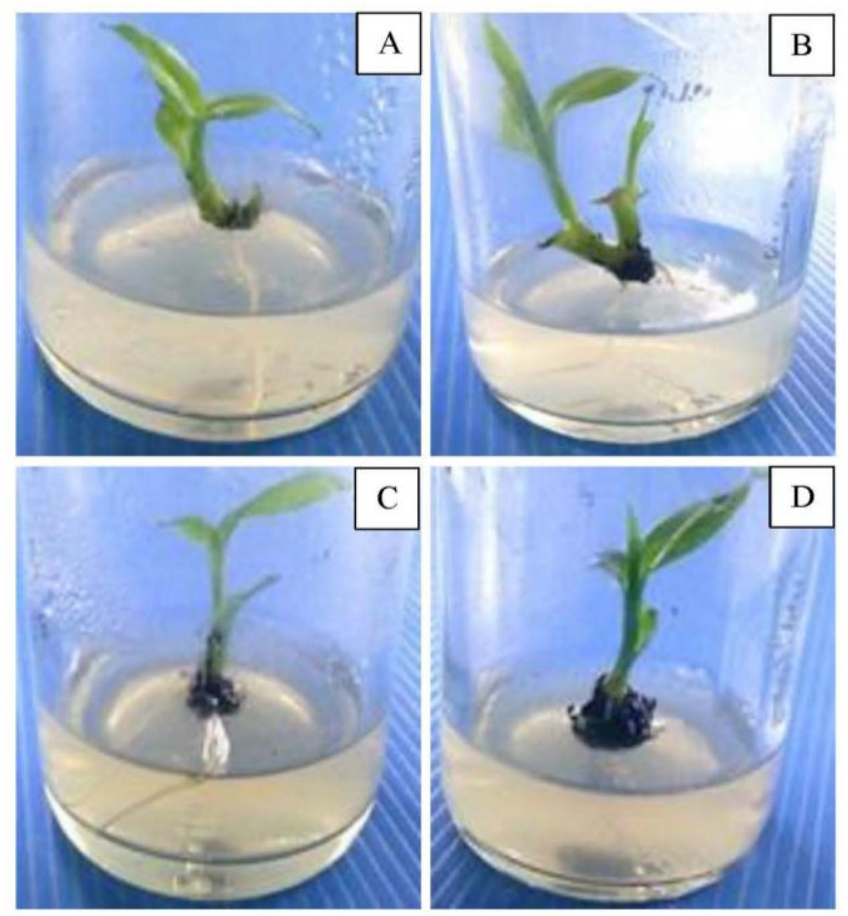

Fig. 2 The characteristics of the roots of the shoots of 'Kluai Nam Thai' cultured on the MS medium with various concentrations of the coconut water after 1 month of culturing.

A) MS medium + coconut water $10 \%$

B) MS medium + coconut water $15 \%$

C) MS medium + coconut water $20 \%$

D) MS medium + coconut water $25 \%$

\section{Discussions}

According to the findings, it was found that the highest number of the roots developed by using the coconut water with the concentration of $20 \%$ averagely was 1.85 roots per plant. The longest length of the roots developed by using the coconut water with the concentration of $10 \%$ was 2.34 centimeters. This was consistent with the study of S. Neera and other [13] who studied the effects of cytokinin and the coconut water on the development of Kaentawan trucks in the sterilized conditions by using the MS medium having the coconut water with the concentrations of $0 \%, 10 \%$, $15 \%$ and $20 \%$ (volume by volume) within the culture period of 1 month. It was found that the highest number of the roots developed by using the recipe with the coconut water $(15 \%)$ was three roots per part. Similarly, T. Jarujit [14] studied the effects of NAA, BA, medium supplement, sucrose and temperature on the growths of the shoots of Lueang Chanthaboon orchids by culturing the shoots with the average height of 1.2 centimeters from the seeds on the MS medium with the coconut water $(15 \%)$ for 16 weeks. It was found that the number of the roots was 2.80 roots, and the average length of the roots was 1.30 centimeters.
Additionally, Hafsan and other [15] studied the effects of the coconut water on the growths of the potatoes in the sterilized conditions by using the MS medium having the coconut water with the concentrations of $0 \%, 5 \%, 10 \%$ and $15 \%$. It was found that the different concentrations of the coconut water resulted in the different developments of the roots. The coconut water with the concentration of $15 \%$ resulted in the highest number of the roots. The plants could effectively develop roots because the percentage of the sugar in the coconut water was high. It was also possible that the ratio of cytokinin and auxin was unbalanced [16].

\section{Recommendations}

\section{A. Recommendations for Practices}

'Kluai Nam Thai' are rare local bananas. Hence, public organizations should promote and reproduce the bananas in order to conserve the species by using the plant tissue culture technique and referring to the findings of this study.

\section{B. Recommendations for Further Research}

The study on the effects of the coconut water on the root induction of 'Kluai Nam Thai' was an experiment conducted in the laboratory. Thus, further studies should experiment on growing the shoots with the roots developed in this study in order to prove that the banana trees are heathy and the trees can grow well as well as to complete this study.

\section{Conclusion}

In this study, the effects of the coconut water with the different concentrations on the root induction of 'Kluai Nam Thai' were studied by culturing the plants for 1 month. It was found that the coconut water with the concentration of $20 \%$ resulted in the highest number of the roots, and the coconut water with the concentration of $10 \%$ resulted in the longest length of the roots. So, the shoots were appropriate for being acclimatization and grown in plots.

\section{References}

[1] P. Suthanukool, "Edible Bananas of Department of Agriculture", $1^{\text {st }}$ Edition, Nonthaburi: Kernkhum Media, 2018.

[2] B. Silayoi, "Banana", Bangkok: Kasetsart University Press, 2015.

[3] P. Chuntaratin, "Plant Tissue Culture for Agricultural Technology", Bangkok: Bangkok Thonburi University, 2013.

[4] D. Boonyakiat. (2004). Plant Hormones. Faculty of Agriculture, Chiang Mai University., CM. [Online]. Available: http://web.agri.cmu.ac.th/hort/course/359311/PP HY10_hormone.htm 
[5] C. Teangpook, "Coconut Juice: Great Natural Food”, Food, Vol.45, no.2, pp. 37-42, 2015.

[6] T. Sangudom, "Growth Regulators and Guidelines for Fruits, Bangkok: Horticulture Research Institute Department of Agriculture, 2016.

[7] O. Selakorn, S. Sutaphan, K. Phasinam, and T. Kassanuk, "The Optimal Concentration of Coconut Water on Multiple Shoot Induction of Musa (AAA group) 'Kluai Nak' In Vitro', YRU Journal of Science and Technology, Vol.5, no.1, pp. 28-33, 2020.

[8] N. Sudhanyaratana, S. Aoki, and K. Rattana, "Tissue Culture and the Analysis of Ploidy Stability of Musa (ABB) 'Namwa Mali-Ong'", SDU Research Journal, Vol.9, pp. 1-14, 2016.

[9] T. Murashige and F. Skoog, "A Revised Medium for Rapid Growth and Bio Assays with Tobacco Tissue Cultures", Physiologia Plantarum, Vol.15, pp. 473-497, 1962.

[10] R. Senavongse, P. Saensouk, and S. Saensouk, "In vitro tissue culture of Dendrobium Kontumense Gagnep", Asia-Pacific Journal of Science and Technology, Vol.19, pp. 399-413, 2014.

[11] A. Enik, Samanhudi and Y. Ahmad, "Coconut Water and IAA Effect on the In Vitro Growth of Tribulus Terrestris L", Acta Universitatis Agriculturae et Silviculturae Mendelianae Brunensis, Vol.67, pp. 9-17, 2019.

[12] O. Selakorn, K. Phasinam, T. Kassanuk, and S. Sutaphan, Influence of Organic Aadditives on Multiple Shoot Formation of Musa (AA group) 'Kluai Nam Thai' In Vitro, Rajabhat Journal of Sciences and Humanities, Vol.21, pp.348-354, 2020.

[13] S. Neera, W. Soonthorn, P. Mongkolpun and P. Hongpukdee, Effect of cytokinins and coconut water on in vitro shoot induction of Kaentawan (Helianthus tuberous L.), Khon Kaen Agriculture Journal, Vol.42, pp. 328-334, 2014.

[14] T. Jarujit, "Effects of NAA BA Growth Supplement, Sucrose and Temperature on Growth of Dendrobium friedericksianum Rchb. f. Seeding", Thesis Master Degree of Science, Ubon Ratchathani: Faculty of Science, Ubon Ratchathani University, 2012.

[15] Hafsan, Muhammad Khalifah Mustami, Masrianya, Isna Rasdianah Aziz and Mustakim, The Utilization of Coconut Water Waste as a Growth Media of the In-Vitro Potato Cutting,
Scientiae Educatia: Journal Pendidikan Sains, Vol.7, pp. 108-116, 2018.

[16] S.A. Bekheet and M.M. Saker, Rapid Mass Micropropagation of Banana, Bulletin of the National Research center, Vol.24, pp. 221-232, 1999. 